Article

\title{
Radical Scavenging Activity of Puerarin: A Theoretical Study
}

\author{
Huakang Zhou ${ }^{1}$, Xiangzhou Li ${ }^{1}$, Yaxuan Shang ${ }^{1}$ and Kai Chen ${ }^{2,3, *(D)}$ \\ 1 School of Materials Science and Engineering, Central South University of Forestry and Technology, \\ Changsha 410004, China; zhouhuakang@126.com (H.Z.); 13808466928@163.com (X.L.); \\ shang_yaxuan@163.com (Y.S.) \\ 2 College of Chemistry and Chemical Engineering, Central South University, Changsha 410083, China \\ 3 State Key Laboratory of Chemical Oncogenomics, Peking University Shenzhen Graduate School, \\ Shenzhen 518055, China \\ * Correspondence: cekchen@scut.edu.cn
}

Received: 28 October 2019; Accepted: 24 November 2019; Published: 26 November 2019

\begin{abstract}
Puerarin is a C-glycoside of daidzein, one of the major bioactive ingredients isolated from the root of Pueraria lobata, which has a wide spectrum of pharmacological effects. Although puerarin is well-known for its effective antioxidant activity, there is seldom a systematic theoretical study on its radical scavenging activity. Herein, the free radical scavenging ability of puerarin was investigated systematically by density functional theory (DFT) calculations. The reaction activity was compared with daidzein as well. Three reaction pathways: hydrogen atom transfer (HAT), single electron transfer followed by proton transfer (SET-PT), and sequential proton loss electron transfer (SPLET) were discussed and compared by thermodynamic parameters such as bond dissociation enthalpy (BDE), ionization potential (IP), proton dissociation enthalpy (PDE), proton affinity (PA), and electron transfer enthalpy (ETE). The reaction kinetics of puerarin with special radicals $\bullet \mathrm{OH}$ and - $\mathrm{OOH}$ were also studied. The results obtained may be of great significance for better understanding the relationship between the antioxidant properties and structural design of puerarin, as well as other antioxidants.
\end{abstract}

Keywords: puerarin; daidzein; antioxidant; DFT; radical scavenging activity

\section{Introduction}

Reactive oxygen species (ROS) are among the most harmful free radicals in the human body, such as hydroxyl radical $(\bullet \mathrm{OH})$, superoxide anion radical $\left(\bullet \mathrm{O}^{2-}\right)$, peroxyl radicals (ROO•), etc. $[1,2]$. If excessive ROS are produced in vivo, the antioxidant system will be out of balance, called oxidative stress, which could damage the structures and functions of the biological macromolecules such as lipids, proteins, RNA, and DNA [3,4]. Numerous human diseases are related to oxidative stress, like aging, atherosclerosis, diabetes, and Parkinson's disease [5,6]. Synthetic antioxidants such as butylated hydroxyanisole (BHA), butylated hydroxytoluene (BHT), propyl gallate, and tert-butyl hydroquinone (TBHQ) are widely used as antioxidants or preservatives in foods, medicines, animal feeds, petroleum products, cosmetics, rubbers, etc. However, synthetic antioxidants often cause toxic and carcinogenic problems $[7,8]$. Hence, the development of more efficient, less toxic, and safer natural antioxidants has attracted broad interest.

Flavonoids are reported to be important natural antioxidants from plants, which have plenty of pharmacological properties such as antioxidant, anticancer, anti-inflammation, vasodilation, alleviating pain, etc., $[9,10]$. Puerarin ( $4^{\prime}, 7-$ dihydroxy-8- $\beta$-D-glucosyliso-flavone) is a C-glycoside of daidzein, easily soluble in water with a solubility of $1.1 \times 10^{-2} \mathrm{M}$ (Figure 1) [11]. It is a major isoflavone extract 
from $P$. lobata roots, has potent antioxidant properties by scavenging free radicals and increasing the activity of superoxide dismutase as well [12]. Cheng et al. found that puerarin could significantly reverse $\mathrm{H}_{2} \mathrm{O}_{2}$-induced oxidative stress injury and decrease ROS production [13]. Bebrevska et al. evaluated the antioxidant activity of $P$. lobata root extract and found it was very efficient and safe in vivo [14]. Tian et al. examined the dynamics of excited states and radicals of puerarin by means of laser flash photolysis and spin-density analysis, which revealed the presence of long-lived puerarin radical surviving longer than milliseconds [15]. Yi and co-workers performed a complete NMR analysis of puerarin and daidzein, and explored the antioxidative activity by bond dissociation enthalpy (BDE) calculations [16]. However, to the best of our knowledge, there is still no systematic theoretical study on the antioxidant activity of puerarin. Herein, a systematic theoretical study on the antioxidant activities of puerarin was carried out to understand the radical scavenging mechanism of this natural product. Considering the relationship between puerarin and daidzein, a comparative study was carried out to help understand the activity.

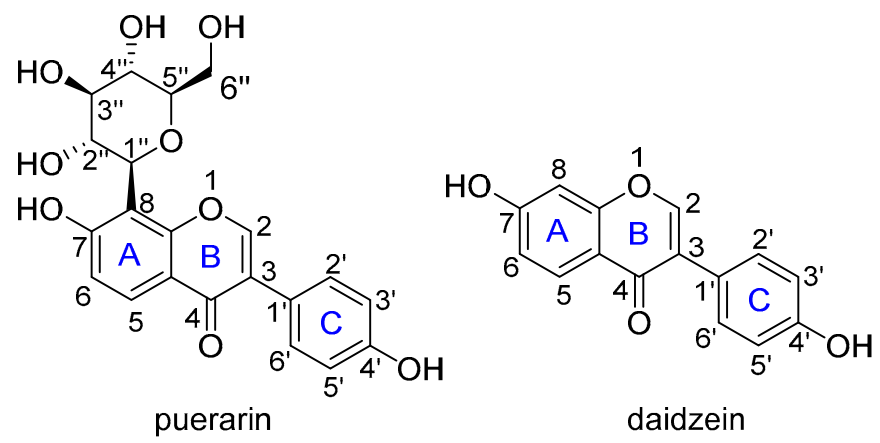

Figure 1. The molecular structure of puerarin and daidzein.

\section{Computational Methods}

Geometry optimization and frequency calculations were performed by M06-2X [17] functional in conjunction with 6-31G(d) basis set in gas phase. Then single point calculations were conducted at M06-2X/6-311++G(d,p) theoretical level in different environments, considering the physiological medium is water while the possible action site could be the lipid membrane. Truhlar's solvation model based on density (SMD) was chosen to account for the solvation effect [18]. Unrestricted calculations were used for open shell systems. Local minima were confirmed without imaginary frequencies, while transition states have only one imaginary frequency. Intrinsic reaction coordinate (IRC) calculations were performed to guarantee the connections between each transition state and the designated local minima. All of the calculations were completed utilizing Gaussian16 code (RevA.03, Gaussian Inc., Wallingford CT, USA) [19]. Optimized structure and frontier molecular orbital plots were produced by applying CYLview2.0 (University of Sherbrooke, Quebec, Canada) [20] or GaussView6.0 (Semichem Inc., Shawnee Mission, Kansas, USA) [21].

Phenolic antioxidants could scavenge free radicals through three possible action mechanisms [22-24]: hydrogen atom transfer (HAT), single electron transfer followed by proton transfer (SET-PT), and sequential proton loss electron transfer (SPLET). For HAT mechanism, phenolic antioxidant $(\mathrm{ArOH})$ reacts with a free radical $(\mathrm{R} \bullet)$ by transferring a hydrogen atom to the free radical through homolytic rupture of the $\mathrm{O}-\mathrm{H}$ bond. Then, the antioxidant reactivity of $\mathrm{ArOH}$ could be evaluated by $\mathrm{BDE}(\mathrm{ArO}-\mathrm{H})$, which could be calculated as follows:

$$
\mathrm{BDE}(\mathrm{ArO}-\mathrm{H})=\mathrm{H}(\mathrm{ArO} \bullet)+\mathrm{H}(\mathrm{H} \bullet)-\mathrm{H}(\mathrm{ArOH})
$$


For the SET-PT mechanism, it involves two steps: electron transfer from ArOH to give radical cation $\left(\mathrm{ArOH}_{\bullet}{ }^{+}\right)$followed by proton transfer from $\mathrm{ArOH} \bullet^{+}$. The antioxidant activity could be described by the ionization potential (IP) and proton dissociation enthalpy (PDE) values:

$$
\begin{gathered}
\mathrm{IP}=\mathrm{H}\left(\mathrm{ArOH} \bullet^{+}\right)+\mathrm{H}\left(\mathrm{e}^{-}\right)-\mathrm{H}(\mathrm{ArOH}) \\
\mathrm{PDE}=\mathrm{H}(\mathrm{ArO} \bullet)+\mathrm{H}\left(\mathrm{H}^{+}\right)-\mathrm{H}\left(\mathrm{ArOH} \bullet^{+}\right)
\end{gathered}
$$

For the SPLET mechanism, it is initiated by proton loss to form anion $\left(\mathrm{ArO}^{-}\right)$and then undergoes electron transfer to give ArO•, which could be revealed by proton affinity (PA) and electron transfer enthalpy (ETE) values:

$$
\begin{aligned}
& \mathrm{PA}=\mathrm{H}\left(\mathrm{ArO}^{-}\right)+\mathrm{H}\left(\mathrm{H}^{+}\right)-\mathrm{H}(\mathrm{ArOH}) \\
& \mathrm{ETE}=\mathrm{H}(\mathrm{ArO} \bullet)+\mathrm{H}\left(\mathrm{e}^{-}\right)-\mathrm{H}\left(\mathrm{ArO}^{-}\right)
\end{aligned}
$$

Here $\mathrm{H}(\mathrm{H} \bullet), \mathrm{H}(\mathrm{ArOH}), \mathrm{H}(\mathrm{ArO} \bullet), \mathrm{H}\left(\mathrm{ArO}^{-}\right)$, and $\mathrm{H}\left(\mathrm{ArOH} \bullet{ }^{+}\right)$are the enthalpies of hydrogen atom, antioxidant, neutral radical, anion, and radical cation, respectively. The enthalpies of proton $\mathrm{H}\left(\mathrm{H}^{+}\right)$ and electron $\mathrm{H}\left(\mathrm{e}^{-}\right)$were obtained from literatures $[25,26]$.

\section{Results and Discussion}

\subsection{Stable Conformation}

The most stable conformations of puerarin and daidzein were obtained after systematic conformational search. The isoflavone scaffold is close to a plane, and there is a small dihedral angle between chromenone and phenyl ring $\mathrm{C},-37.9{ }^{\circ} \mathrm{C}$ for puerarin, or $-38.1{ }^{\circ} \mathrm{C}$ for daidzein (Figure 2). In puerarin, the bond length of 7-O-H is a little longer than that of $4^{\prime}-\mathrm{O}-\mathrm{H}$, because of a weak intramolecular hydrogen bond between 7-OH and the glycosyl group. The glycosyl group is in chair conformation, where four hydroxyl groups form three intramolecular hydrogen bonds. Introduction of a glucose moiety makes puerarin strongly hydrophilic. For example, the solubility of puerarin in water, $1.1 \times 10^{-2} \mathrm{M}$ [11], is much better than that of daidzein, only $5.3 \times 10^{-6} \mathrm{M}$ [27], which makes puerarin's oral bioavailability much better than daidzein [28].

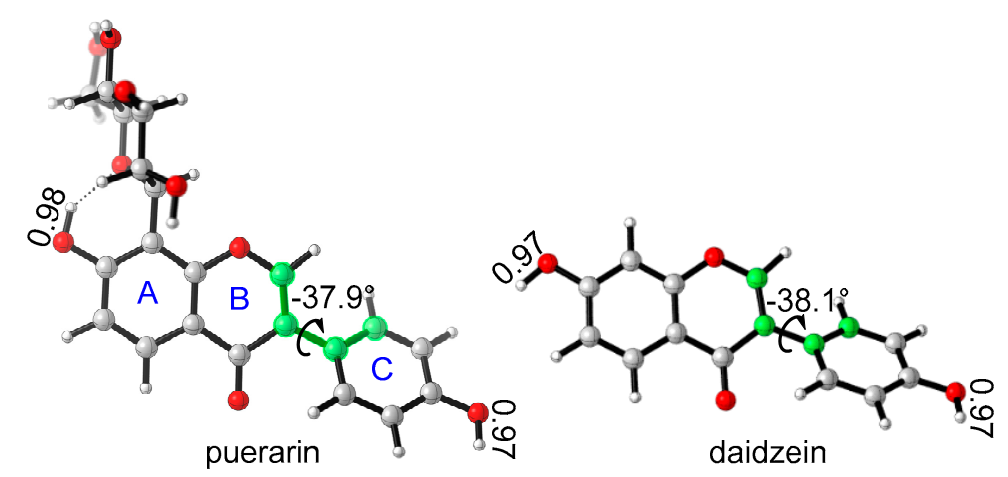

Figure 2. The stable conformations of puerarin and daidzein.

\subsection{Frontier Molecular Orbital Analysis}

Frontier molecular orbitals (FMO) play important roles in the reactivities of molecules [29-31]. As shown in Figure 3, FMO orbitals are not distributed on the glycosyl group of puerarin, and the orbital shapes of puerarin and daidzein are similar, which indicates the glycosyl group unlikely participated in the reaction. Thus, the glycosyl group is not considered in the following calculations. In both molecules, the highest occupied molecular orbital (HOMO) is mainly distributed on the phenyl ring $\mathbf{C}$, while the lowest unoccupied molecular orbital (LUMO) largely lies on the chromenone moiety. As antioxidant mostly functioned as electron donor to provide electron to radical, the phenyl ring $\mathbf{C}$ 
should play a more important role in radical scavenging reactions. The HOMO-LUMO gaps were close, $6.5 \mathrm{eV}$ and $6.4 \mathrm{eV}$ for puerarin and daidzein, respectively, which were similar to that of another natural antioxidant, resveratrol, $6.3 \mathrm{eV}$ [32].
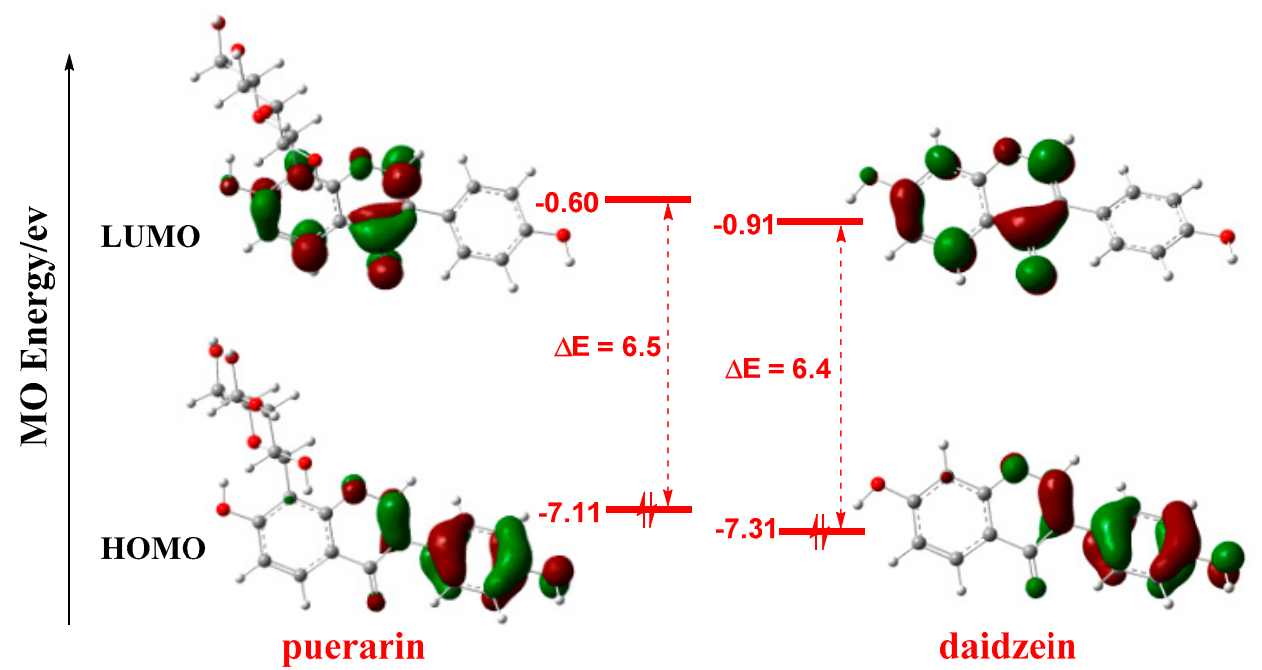

Figure 3. FMO of puerarin and daidzein. Isovalue for MO surface: 0.05, orbital energies in eV. FMO: frontier molecular orbital; MO: molecular orbital; HOMO: highest occupied molecular orbital; LUMO: lowest unoccupied molecular orbital.

\subsection{HAT Mechanism}

$\mathrm{BDE}(\mathrm{ArO}-\mathrm{H})$ is one of the most important indicators to evaluate HAT mechanism (Table 1). $\mathrm{BDE}\left(4^{\prime}-\mathrm{O}-\mathrm{H}\right)$ of puerarin and daidzein in water are 88.2 and $88.3 \mathrm{kcal} / \mathrm{mol}$, respectively, a little lower than $\mathrm{BDE}(7-\mathrm{O}-\mathrm{H})$, which indicates $4^{\prime}-\mathrm{OH}$ is the primary reaction site, similar to previous studies on other isoflavonoids $[33,34]$. $\mathrm{BDE}(\mathrm{O}-\mathrm{H})$ of phenol has been determined by several experiments, and the recommended value is $\sim 88.7 \mathrm{kcal} / \mathrm{mol}[35,36]$, very close to $\mathrm{BDE}\left(4^{\prime}-\mathrm{O}-\mathrm{H}\right)$ here. A stronger bond of 7-OH than $4^{\prime}-\mathrm{OH}$ could be explained by the electron-withdrawing effect of pyrone moiety, which leads to puerarin-7-O• radical less stable than puerarin-4'-O• radical. BDE in polar environment is a little larger than that in non-polar solvent. However, the difference of BDE values among different solvents is still within $3.0 \mathrm{kcal} / \mathrm{mol}$, similar to previous studies on other similar polyphenols [33,37,38]. As the glucose moiety sits far away from the reaction site, the antioxidant activities of puerarin and daidzein should be similar, which was also supported by the values of $\operatorname{BDE}\left(4^{\prime}-\mathrm{O}-\mathrm{H}\right)$.

Table 1. The O-H BDEs of puerarin and daidzein in gas phase and different solvents (Units: kcal/mol).

\begin{tabular}{cccc}
\hline Sites & Gas & Benzene & Water \\
\hline puerarin & & & \\
$4^{\prime}-\mathrm{OH}$ & 87.3 & 86.6 & 88.2 \\
7-OH & 97.0 & 96.5 & 96.8 \\
daidzein & & & \\
$4^{\prime}-\mathrm{OH}$ & 86.9 & 86.4 & 88.3 \\
7-OH & 91.6 & 91.7 & 95.3 \\
\hline
\end{tabular}

\subsection{SET-PT Mechanism}

In SET-PT mechanism, an electron is first transferred from natural antioxidant $(\mathrm{ArOH})$ to a free radical leading to the formation of cation radical $\left(\mathrm{ArOH} \bullet \bullet^{+}\right)$, then a proton is transferred from $\mathrm{ArOH} \bullet+$ to give ArO•, described by IP and PDE, respectively. Different from BDE values, the solvent polarity has significant effects on the IP and PDE values (Table 2), which could be attributed to the high solvation enthalpies of proton and electron $[39,40]$. The IP values of puerarin in gas phase, benzene, and water 
are $179.9,154.7$, and $113.3 \mathrm{kcal} / \mathrm{mol}$, respectively. The sequence of PDEs in different solvents are analogous with those of IPs and the lowest PDE is in water. The IP values of daidzein are close to those of puerarin. As IP values are larger than PDE values in solvent, the first step is thermodynamically significant for SET-PT mechanism. For both molecules, IPs in solvent are at least $25 \mathrm{kcal} / \mathrm{mol}$ higher than the lowest BDE, which indicates the SET-PT pathway is not as favorable as the HAT pathway. This conclusion is similar to the references, which confirms the accuracy of this work $[33,37,38]$.

Table 2. Ionization potentials (IPs) and proton dissociation enthalpies (PDEs) of puerarin and daidzein in gas phase and different solvents.

\begin{tabular}{ccccccc}
\hline \multirow{2}{*}{ Sites } & \multicolumn{3}{c}{ IP (kcal/mol) } & & \multicolumn{2}{c}{ PDE (kcal/mol) } \\
\cline { 2 - 7 } & Gas & Benzene & Water & Gas & Benzene & Water \\
\hline puerarin & 179.9 & 154.7 & 113.3 & & & \\
4'-OH & & & & 220.8 & 29.8 & 17.6 \\
7-OH & & & 113.4 & 230.5 & 39.7 & 26.1 \\
daidzein & 178.9 & 153.9 & & 213.0 & 21.9 & 9.1 \\
4'-OH & & & & 217.4 & 27.0 & 15.8 \\
7-OH & & & & & & \\
\hline
\end{tabular}

\subsection{SPLET Mechanism}

SPLET mechanism also plays an important role in free radical scavenging reactions (Table 3). The calculated PAs and ETEs are listed in Table 3. Similar to PDEs, PA values show a significant decrease from gas phase to solvent, which could be explained by the large solvation enthalpies of proton and anion. For both molecules, in gas phase and non-polar solvent, PA $(7-\mathrm{OH})$ is larger than ETE $\left(4^{\prime}-\mathrm{OH}\right)$, while in polar solvents the former is lower than the latter. It means that in water, the determining step in SPLET is the second step thermodynamically. As ETE $\left(4^{\prime}-\mathrm{OH}\right)$ is even lower than BDE $\left(4^{\prime}-\mathrm{OH}\right)$, SPLET pathway is more favorable than HAT pathway in water. However, in non-polar solvent, the smaller PA values, $\mathrm{PA}(7-\mathrm{OH})$ are larger than $\mathrm{BDE}\left(4^{\prime}-\mathrm{OH}\right)$, thus HAT should be the dominant pathway. These results agree well with the previous studies of flavonoids and isoflavonoids $[33,37,38]$.

Table 3. Proton affinities (PAs) and electron transfer enthalpies (ETEs) of puerarin and daidzein in gas phase and different solvents.

\begin{tabular}{|c|c|c|c|c|c|c|}
\hline \multirow{2}{*}{ Sites } & \multicolumn{3}{|c|}{ PA (kcal/mol) } & \multicolumn{3}{|c|}{ ETE (kcal/mol) } \\
\hline & Gas & Benzene & Water & Gas & Benzene & Water \\
\hline \multicolumn{7}{|l|}{ puerarin } \\
\hline $4^{\prime}-\mathrm{OH}$ & 338.0 & 103.0 & 48.8 & 62.7 & 81.4 & 82.1 \\
\hline 7-OH & 317.0 & 87.3 & 40.8 & 93.4 & 107.1 & 98.7 \\
\hline \multicolumn{7}{|l|}{ daidzein } \\
\hline $4^{\prime}-\mathrm{OH}$ & 332.2 & 95.0 & 39.1 & 59.7 & 80.8 & 83.4 \\
\hline 7-OH & 319.9 & 85.1 & 32.9 & 76.4 & 95.7 & 96.3 \\
\hline
\end{tabular}

The above analysis suggested that in water SPLET pathway is dominant, while in non-polar solvent, HAT pathway is preferred. As in water, the determining step of SPLET pathway is the second step thermodynamically, ETE values of the reaction site, $4^{\prime}-\mathrm{OH}$, are close, 82.1 and $83.4 \mathrm{kcal} / \mathrm{mol}$ for puerarin and daidzein, respectively, while in non-polar solvent, BDE values of the reaction site, $4^{\prime}-\mathrm{OH}$, are 86.6 and $86.4 \mathrm{kcal} / \mathrm{mol}$ for puerarin and daidzein, respectively. Thus, puerarin and daidzein have very similar antioxidant activity, which was also supported by experimental results $[27,41]$. Considering the solubility and bioavailability of puerarin is much better than daidzein, puerarin should have a better antioxidant. 


\subsection{Kinetics of Free Radical Scavenging by Puerarin}

To have a better understanding of the radical scavenging properties of puerarin, the kinetics of puerarin with representative free radicals was studied. Hydroxyl radical $(\bullet \mathrm{OH})$ and hydroperoxyl radical $(\bullet \mathrm{OOH})$ were chosen as the two representative $\mathrm{ROS}$, which reacted with puerarin as following:

$$
\begin{gathered}
\text { Puerarin-OH }+\bullet \mathrm{OH} \rightarrow \text { Puerarin }-\mathrm{O} \bullet+\mathrm{H}_{2} \mathrm{O} \\
\text { Puerarin-OH }+\bullet \mathrm{OOH} \rightarrow \text { Puerarin }-\mathrm{O} \bullet+\mathrm{H}_{2} \mathrm{O}_{2}
\end{gathered}
$$

As $\bullet \mathrm{OH}$ is much more reactive than $\bullet \mathrm{OOH}$, the reaction barrier of puerarin with $\bullet \mathrm{OH}$ is much lower than that with $\bullet \mathrm{OOH}$ (Table 4, Table S1). In the molecule, $4^{\prime}-\mathrm{OH}$ is more reactive than $7-\mathrm{OH}$. For example, in water, the free energy barrier of $4^{\prime}-\mathrm{OH}$ with $\bullet \mathrm{OH}$ is $12.2 \mathrm{kcal} / \mathrm{mol}$ lower than that of $7-\mathrm{OH}$ with $\bullet \mathrm{OH}$. The former is as low as $3.0 \mathrm{kcal} / \mathrm{mol}$, which suggests a diffusion-controlled process, according to the transition state theory [42,43]. Although the reaction barriers are less than $20 \mathrm{kcal} / \mathrm{mol}$ in water, the reactions with $\bullet \mathrm{OOH}$ are endergonic except $4^{\prime}-\mathrm{OH}$ with $\bullet \mathrm{OOH}$, which suggests puerarin is not an efficient scavenger of $\bullet \mathrm{OOH}$. Transition state structures are shown in Figure 4. In TS $\left(4^{\prime}-\mathrm{OH}-\bullet \mathrm{OH}\right)$, the forming and breaking $\mathrm{O}-\mathrm{H}$ bonds are 1.37 and $1.05 \AA$ in length, while in TS $\left(4^{\prime}-\mathrm{OH}-\bullet \mathrm{OOH}\right)$, the forming and breaking $\mathrm{O}-\mathrm{H}$ bonds are 1.22 and $1.16 \AA$ in length. The forming $\mathrm{O}-\mathrm{H}$ bond in $\mathrm{TS}\left(4^{\prime}-\mathrm{OH}-\bullet \mathrm{OH}\right)$ or $\mathrm{TS}(7-\mathrm{OH}-\bullet \mathrm{OH})$ is longer than that in the corresponding transition structure with $\bullet \mathrm{OOH}$, indicating the former is an earlier transition state than the latter.

\begin{tabular}{|c|c|c|c|c|c|c|}
\hline \multirow{2}{*}{ Sites } & \multicolumn{3}{|c|}{$\Delta \mathrm{G}^{\neq}(\mathrm{kcal} / \mathrm{mol})$} & \multicolumn{3}{|c|}{$\Delta \mathrm{G}(\mathrm{kcal} / \mathrm{mol})$} \\
\hline & Gas & Benzene & Water & Gas & Benzene & Water \\
\hline \multicolumn{7}{|c|}{ Reaction with $\bullet \mathrm{OH}$} \\
\hline $4^{\prime}-\mathrm{OH}$ & 6.8 & 8.0 & 3.0 & -29.7 & -31.2 & -33.0 \\
\hline $7-\mathrm{OH}$ & 10.1 & 11.8 & 15.2 & -20.9 & -22.2 & -25.3 \\
\hline \multicolumn{7}{|c|}{ Reaction with $\bullet \mathrm{OOH}$} \\
\hline $4^{\prime}-\mathrm{OH}$ & 16.6 & 18.1 & 19.4 & 1.8 & 0.9 & -0.5 \\
\hline $7-\mathrm{OH}$ & 22.4 & 25.4 & 26.8 & 10.6 & 9.9 & 7.1 \\
\hline
\end{tabular}

Table 4. Free energy barriers for the reaction of puerarin with $\bullet \mathrm{OH}$ or $\bullet \mathrm{OOH}$ in gas phase and solution.
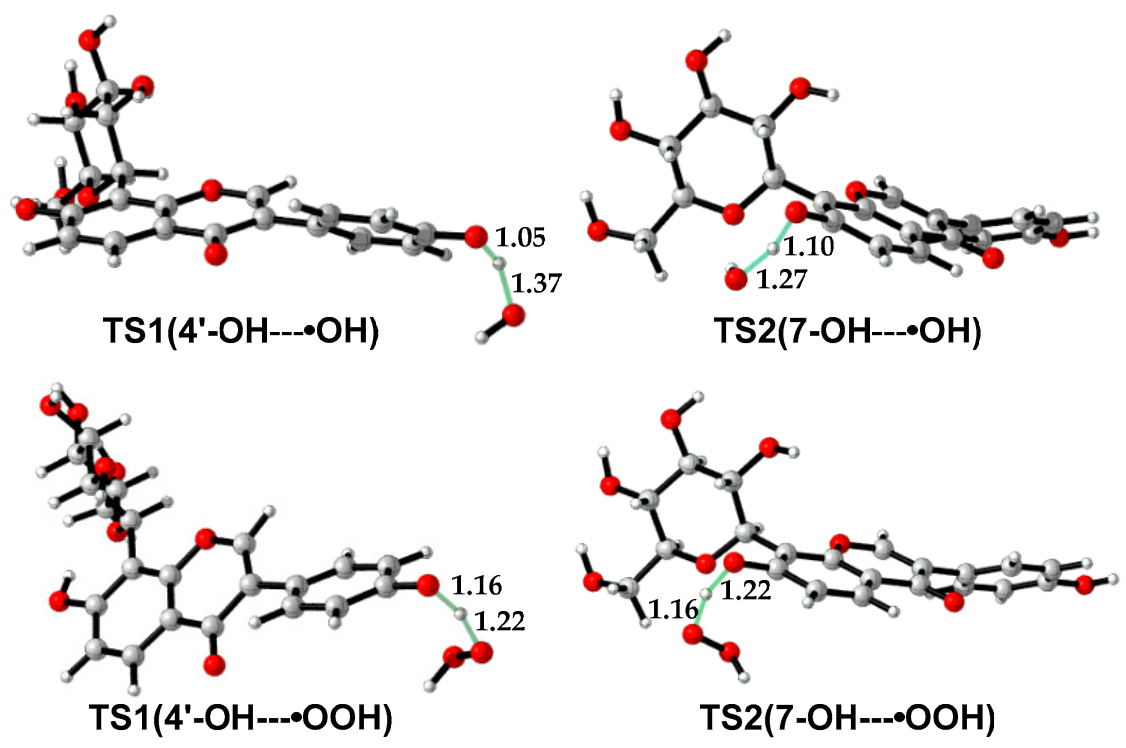

Figure 4. Transition state structures in the reactions of puerarin with radical $\bullet \mathrm{OH}$ or $\bullet \mathrm{OOH}$. 


\section{Conclusions}

The radical scavenging activity of puerarin was investigated under the theoretical level of M062X/6-311++G(d,p)//M062X/6-31G(d). Three reaction mechanisms were considered: HAT, SET-PT, and SPLET. It reveals that HAT should be the preferred mechanism in non-polar solvents, while SPLET would be more favorable in polar media, thermodynamically. The reaction activity was compared with daidzein, which shows puerarin and daidzein have very similar antioxidant activity. However, as puerarin has better solubility and bioavailability, puerarin should be a better antioxidant than daidzein. The reaction kinetics of puerarin with $\bullet \mathrm{OH}$ or $\bullet \mathrm{OOH}$ radicals were also investigated. The reactions with $\bullet \mathrm{OH}$ have much lower energy barrier than those with $\bullet \mathrm{OOH}$. All these results suggests $4^{\prime}$-OH is perhaps the most reactive site to scavenge radicals, which agrees well with previous studies. These results might be helpful for interpreting puerarin's antioxidant activity and for further designing new potential derivatives.

Supplementary Materials: The following are available online at http://www.mdpi.com/2076-3921/8/12/590/s1, Table S1: Thermal energies of all stationary points and Cartesian coordinates for all stationary points.

Author Contributions: Conceptualization, H.Z. and K.C.; methodology, H.Z.; software, H.Z.; validation, H.Z., Y.S. and K.C.; formal analysis, H.Z.; investigation, H.Z.; resources, H.Z.; data curation, H.Z.; writing-original draft preparation, H.Z.; writing-review and editing, K.C. and X.L.; visualization, Y.S.; supervision, K.C.; project administration, H.Z.; funding acquisition, K.C. and X.L.

Funding: Financial support for this research was provided by Natural Science Foundation of Hunan Province (NO. 2018JJ3868), the National Key R\&D Program of China (NO. 2016YFD0600805).

Acknowledgments: We would like to appreciate Central South University, Central South University of Forestry and Technology and the State Key Laboratory of Chemical Genomics of Peking University Shenzhen Graduate School for funding this project. Thanks to the National Supercomputer Centers (Guangzhou \& Lvliang) for supporting the project's computing source.

Conflicts of Interest: There are no conflicts to declare.

\section{References}

1. Poprac, P.; Jomova, K.; Simunkova, M.; Kollar, V.; Rhodes, C.J.; Valko, M. Targeting Free Radicals in Oxidative Stress-Related Human Diseases. Trends Pharmacol. Sci. 2017, 38, 592-607. [CrossRef] [PubMed]

2. Sies, H.; Berndt, C.; Jones, D.P. Oxidative Stress. Annu. Rev. Biochem. 2017, 86, 715-748. [CrossRef] [PubMed]

3. Choudhury, F.K.; Rivero, R.M.; Blumwald, E.; Mittler, R. Reactive oxygen species, abiotic stress and stress combination. Plant J. 2017, 90, 856-867. [CrossRef] [PubMed]

4. Liu, Z.; Ren, Z.; Zhang, J.; Chuang, C.-C.; Kandaswamy, E.; Zhou, T.; Zuo, L. Role of ROS and nutritional antioxidants in human diseases. Front. Physiol. 2018, 9. [CrossRef] [PubMed]

5. Stockwell, B.R.; Friedmann Angeli, J.P.; Bayir, H.; Bush, A.I.; Conrad, M.; Dixon, S.J.; Fulda, S.; Gascón, S.; Hatzios, S.K.; Kagan, V.E.; et al. Ferroptosis: A Regulated Cell Death Nexus Linking Metabolism, Redox Biology, and Disease. Cell 2017, 171, 273-285. [CrossRef] [PubMed]

6. Cheignon, C.; Tomas, M.; Bonnefont-Rousselot, D.; Faller, P.; Hureau, C.; Collin, F. Oxidative stress and the amyloid beta peptide in Alzheimer's disease. Redox Biol. 2018, 14, 450-464. [CrossRef]

7. Caleja, C.; Barros, L.; Antonio, A.L.; Oliveira, M.B.P.P.; Ferreira, I.C.F.R. A comparative study between natural and synthetic antioxidants: Evaluation of their performance after incorporation into biscuits. Food Chem. 2017, 216, 342-346. [CrossRef]

8. Taslimi, P.; Gulçin, İ. Antioxidant and anticholinergic properties of olivetol. J. Food Biochem. 2018, 42, e12516. [CrossRef]

9. Pisoschi, A.M.; Pop, A. The role of antioxidants in the chemistry of oxidative stress: A. review. Eur. J. Med. Chem. 2015, 97, 55-74. [CrossRef]

10. Eghbaliferiz, S.; Iranshahi, M. Prooxidant Activity of Polyphenols, Flavonoids, Anthocyanins and Carotenoids: Updated Review of Mechanisms and Catalyzing Metals. Phytother. Res. 2016, 30, 1379-1391. [CrossRef]

11. Wang, L.-H.; Cheng, Y.-Y. Solubility of Puerarin in Water, Ethanol, and Acetone from (288.2 to 328.2) K. J. Chem. Eng. Data 2005, 50, 1375-1376. [CrossRef] 
12. Liu, C.-M.; Ma, J.-Q.; Sun, Y.-Z. Protective role of puerarin on lead-induced alterations of the hepatic glutathione antioxidant system and hyperlipidemia in rats. Food Chem. Toxicol. 2011, 49, 3119-3127. [CrossRef] [PubMed]

13. Cheng, Y.; Leng, W.; Zhang, J. Protective Effect of Puerarin against Oxidative Stress Injury of Neural Cells and Related Mechanisms. Med. Sci. Monit. 2016, 22, 1244-1249. [CrossRef] [PubMed]

14. Bebrevska, L.; Foubert, K.; Hermans, N.; Chatterjee, S.; Van Marck, E.; De Meyer, G.; Vlietinck, A.; Pieters, L.; Apers, S. In vivo antioxidative activity of a quantified Pueraria lobata root extract. J. Ethnopharmacol. 2010, 127, 112-117. [CrossRef]

15. Tian, Y.-X.; Han, R.-M.; Fu, L.-M.; Zhang, J.-P.; Skibsted, L.H. Radical Dynamics of Puerarin as Revealed by Laser Flash Photolysis and Spin Density Analysis. J. Phys. Chem. B 2008, 112, 2273-2280. [CrossRef]

16. Yi, Y.; Adrjan, B.; Li, J.; Hu, B.; Roszak, S. NMR studies of daidzein and puerarin: Active anti-oxidants in traditional Chinese medicine. J. Mol. Model. 2019, 25, 202. [CrossRef]

17. Zhao, Y.; Truhlar, D.G. The M06 suite of density functionals for main group thermochemistry, thermochemical kinetics, noncovalent interactions, excited states, and transition elements: Two new functionals and systematic testing of four M06-class functionals and 12 other functionals. Theor. Chem. Acc. 2008, 120, 215-241.

18. Marenich, A.V.; Cramer, C.J.; Truhlar, D.G. Universal Solvation Model Based on Solute Electron Density and on a Continuum Model of the Solvent Defined by the Bulk Dielectric Constant and Atomic Surface Tensions. J. Phys. Chem. B 2009, 113, 6378-6396. [CrossRef]

19. Frisch, M.J.; Trucks, G.W.; Schlegel, H.B.; Scuseria, G.E.; Robb, M.A.; Cheeseman, J.R.; Scalmani, G.; Barone, V.; Petersson, G.A.; Nakatsuji, H.; et al. Gaussian 16 Rev. A.03; Gaussian Inc.: Wallingford, CT, USA, 2016.

20. Legault, C.Y. CYLview, 2.0. 2009. Available online: http://www.cylview.org (accessed on 20 September 2019).

21. Dennington, R.; Keith, T.A.; Millam, J.M. GaussView, 6th ed.; Semichem Inc.: Shawnee Mission, KS, USA, 2016.

22. Galano, A. Free radicals induced oxidative stress at a molecular level: The current status, challenges and perspectives of computational chemistry based protocols. J. Mex. Chem. Soc. 2015, 59, 231-262. [CrossRef]

23. Leopoldini, M.; Russo, N.; Toscano, M. The molecular basis of working mechanism of natural polyphenolic antioxidants. Food Chem. 2011, 125, 288-306. [CrossRef]

24. Nenadis, N.; Tsimidou, M.Z. Contribution of DFT computed molecular descriptors in the study of radical scavenging activity trend of natural hydroxybenzaldehydes and corresponding acids. Food Res. Int. 2012, 48, 538-543. [CrossRef]

25. Bartmess, J.E. Thermodynamics of the Electron and the Proton. J. Phys. Chem. 1994, 98, 6420-6424. [CrossRef]

26. Rimarčík, J.; Lukeš, V.; Klein, E.; Ilčin, M. Study of the solvent effect on the enthalpies of homolytic and heterolytic N-H bond cleavage in p-phenylenediamine and tetracyano-p-phenylenediamine. J. Mol. Struct. THEOCHEM 2010, 952, 25-30. [CrossRef]

27. Han, R.-M.; Tian, Y.-X.; Liu, Y.; Chen, C.-H.; Ai, X.-C.; Zhang, J.-P.; Skibsted, L.H. Comparison of Flavonoids and Isoflavonoids as Antioxidants. J. Agric. Food Chem. 2009, 57, 3780-3785. [CrossRef]

28. Liang, X.-L.; Zhao, L.-J.; Liao, Z.-G.; Zhao, G.-W.; Zhang, J.; Chao, Y.-C.; Yang, M.; Yin, R.-L. Transport properties of puerarin and effect of Radix Angelicae Dahuricae extract on the transport of puerarin in Caco-2 cell model. J. Ethnopharmacol. 2012, 144, 677-682. [CrossRef]

29. Wang, G.; Xue, Y.; An, L.; Zheng, Y.; Dou, Y.; Zhang, L.; Liu, Y. Theoretical study on the structural and antioxidant properties of some recently synthesised 2,4,5-trimethoxy chalcones. Food Chem. 2015, 171, 89-97. [CrossRef]

30. Houk, K.N. Frontier molecular orbital theory of cycloaddition reactions. Acc. Chem. Res. 1975, 8, 361-369. [CrossRef]

31. Xue, Y.; Liu, Y.; Luo, Q.; Wang, H.; Chen, R.; Liu, Y.; Li, Y. Antiradical activity and mechanism of coumarin-chalcone hybrids: Theoretical insights. J. Phys. Chem. A 2018, 122, 8520-8529. [CrossRef]

32. Shang, Y.; Zhou, H.; Li, X.; Zhou, J.; Chen, K. Theoretical studies on the antioxidant activity of viniferifuran. New J. Chem. 2019, 43, 15736-15742. [CrossRef]

33. Zheng, Y.-Z.; Deng, G.; Guo, R.; Fu, Z.-M.; Chen, D.-F. Theoretical insight into the antioxidative activity of isoflavonoid: The effect of the C2=C3 double bond. Phytochemistry 2019, 166, 112075. [CrossRef]

34. Zhang, J.; Du, F.; Peng, B.; Lu, R.; Gao, H.; Zhou, Z. Structure, electronic properties, and radical scavenging mechanisms of daidzein, genistein, formononetin, and biochanin A: A density functional study. J. Mol. Struc. THEOCHEM 2010, 955, 1-6. [CrossRef] 
35. Zhu, Q.; Zhang, X.-M.; Fry, A.J. Bond dissociation energies of antioxidants. Polym. Degrad. Stab. 1997, 57, 43-50. [CrossRef]

36. Bordwell, F.G.; Liu, W.-Z. Solvent Effects on Homolytic Bond Dissociation Energies of Hydroxylic Acids. J. Am. Chem. Soc. 1996, 118, 10819-10823. [CrossRef]

37. Vo, Q.V.; Nam, P.C.; Thong, N.M.; Trung, N.T.; Phan, C.-T.D.; Mechler, A. Antioxidant Motifs in Flavonoids: $\mathrm{O}-\mathrm{H}$ versus C-H Bond Dissociation. ACS Omega 2019, 4, 8935-8942. [CrossRef]

38. Zheng, Y.-Z.; Deng, G.; Chen, D.-F.; Guo, R.; Lai, R.-C. The influence of $\mathrm{C} 2=\mathrm{C} 3$ double bond on the antiradical activity of flavonoid: Different mechanisms analysis. Phytochemistry 2019, 157, 1-7. [CrossRef]

39. Fifen, J.J.; Nsangou, M.; Dhaouadi, Z.; Motapon, O.; Jaidane, N. Solvent effects on the antioxidant activity of 3,4-dihydroxyphenylpyruvic acid: DFT and TD-DFT studies. Comput. Theor. Chem. 2011, 966, 232-243. [CrossRef]

40. Marković, S.; Tošović, J. Comparative study of the antioxidative activities of caffeoylquinic and caffeic acids. Food Chem. 2016, 210, 585-592. [CrossRef]

41. Zhao, L.; Wang, Y.; Liu, J.; Wang, K.; Guo, X.; Ji, B.; Wu, W.; Zhou, F. Protective Effects of Genistein and Puerarin against Chronic Alcohol-Induced Liver Injury in Mice via Antioxidant, Anti-inflammatory, and Anti-apoptotic Mechanisms. J. Agric. Food Chem. 2016, 64, 7291-7297. [CrossRef]

42. Eyring, H. The activated complex in chemical reactions. J. Chem. Phys. 1935, 3, 107-115. [CrossRef]

43. Hammond, G.S. A Correlation of Reaction Rates. J. Am. Chem. Soc. 1955, 77, 334-338. [CrossRef]

(C) 2019 by the authors. Licensee MDPI, Basel, Switzerland. This article is an open access article distributed under the terms and conditions of the Creative Commons Attribution (CC BY) license (http://creativecommons.org/licenses/by/4.0/). 